\section{Sudden cardiac arrest in the young - a call to action}

To the Editor: Sudden cardiac arrest (SCA) in athletes has once again been brought into the spotlight as a result of the recent widely publicised collapse and resuscitation of Fabrice Muambo during a FA Cup soccer match in the United Kingdom. The efforts of the trained medical responders in his successful resuscitation must be applauded. This incident resulted in the South African Premier Soccer League announcing more rigorous screening of players as a primary prevention measure. Sadly, Muambo's case was followed by the sudden cardiac death of Olympic swimmer Alexander Dale Oen.

Electrocardiographic screening of athletes for cardiac abnormalities forms part of a sound primary prevention strategy. ${ }^{1}$ A major remaining challenge is the unpredictability of SCA in unscreened athletes, as only a minority will be screened. Another cause of SCA, commotion cordis, can occur when young athletes with structurally normal hearts sustain a blow to the chest. Immediate chest compressions and early defibrillation therefore remains an extremely important aspect of secondary prevention.

Maron et al., ${ }^{2}$ looking at the global epidemiology of commotion cordis to compare the USA with other countries, found that soccer, cricket, hockey and rugby are the most common causes internationally. These are all popular sports played in South Africa.

Reviewing the management of sudden cardiac arrest on the football field, Krameret et al. ${ }^{3}$ made recommendations for the on-field emergency management of these cases. While some international sports governing bodies, for example FIFA, have started to introduce these measures, it has not become common practice in South African schools, universities, clubs and institutions dealing with young athletes.

We are therefore of the opinion that most young South African athletes practise and participate in sport without adequate contingency plans in place that will ensure early recognition of cardiac arrest, initiation of immediate chest compressions, and defibrillation within 3 - 5 minutes.

The continuing unfortunate and untimely deaths of young, healthy athletes should serve as a reminder to the medical fraternity of our role as advocates to increase awareness, and empower our communities through training to act timeously and efficiently as first responders. Will the dust settle, only to be temporarily stirred again when the next tragic incident occurs?

Conflict of interest. The authors have no conflict of interest to declare.

\section{J A Slabbert}

Worcester Hospital and Stellenbosch University

Western Cape

jaco.a.slabbert@gmail.com

\section{L de Klerk \\ PO Box 3529 \\ Matieland \\ 7602}

1. Corrado D, Drezner J, Basso C. Strategies for the prevention of sudden cardiac death during sports. Eur J Cardiovasc Prev Rehabil 2011;18(2):194-196.

Maron BJ, Ahluwalia A, Haas TS, Semsarian C, Link MS, Estes NA 3rd. Global epidemiology and demographics of commotio cordis. Heart Rhythm 2011;8(12):1969-1971.

Kramer E, Dvorak J, Kloeck W. Review of the management of sudden cardiac arrest on the football field. Br I Sports Med 2010;44(8):540-545.

S Afr Med J 2012;102(8):640. DOI:10.7196/SAMJ.6062

\section{Register on the Mental Health Information Centre of Southern Africa database}

To the Editor: Nearly half a million South Africans look online for solutions to mental health problems every month. The Mental Health Information Centre (MHIC) of Southern Africa aims to provide the most complete and up-to-date online directory of mental health service providers in sub-Saharan Africa. This online service allows anyone to search for a mental health service provider in their area. The MHIC now invites you to list yourself on our database by visiting www.mentalhealthsa.org.za. You can list yourself in a number of categories and sub-categories, allowing users to find you directly by your field of expertise and interests. For privacy reasons your e-mail address and mobile number will remain hidden. Once registered, you will receive an e-mail with detailed instructions about the next steps.

If you have any queries, please do not hesitate to contact us at the Mental Health Information Centre of Southern Africa (MHIC), PO Box 19063, Tygerberg, 7505, South Africa. Tel: +27 (0)21 938-9229, fax: +27 (0)21 931-4172, e-mail: mhic@sun.ac.za.

\section{Janine Roos}

Mental Health Information Centre of Southern Africa Department of Psychiatry

Stellenbosch University

jroos@sun.ac.za

S Afr Med J 2012;102(8):640. DOI:10.7196/SAMJ.6069

\section{Is Hahnemann's therapeutic system a mystica?}

To the Editor: I refer to the recent editorial by Professor Van Niekerk on traditional healers in which Hahnemann's system, or homeopathic therapeutics (HTS), is termed a 'mystica', a religious belief. ${ }^{1}$

HTS arose out of therapeutic uncertainty - how to match, akin to a pass word, a therapy with a disease of a particular patient. Hahnemann discovered in 1790 the experimental methodology termed provings, the homeopathic pathogenic trial (HPT), on disagreeing with the Scottish Hippocrates, Cullen, on the action of Peruvian bark. Hahnemann's intuitive ingestion of bark elicited symptoms and signs of malaria, the HPT. Thus, bark induces a mild similar artificial disease which cures the similar severe disease of the patient - the age-old theory, the similarity. During an HPT, knowledge and experience of a medicine's specific actions are elicited via the healthy, linking diagnosis and therapy prior to its clinical application; thus, specific therapeutics (SRx). The similarity as guiding principle means matching an SRx with the disease of the patient to achieve a successful clinical outcome, which links the diagnosis, therapy and outcome, ${ }^{2}$ approximating therapeutic certainty.

The validity of HTS can be analysed conceptually by the sciences, and the applied sciences. Medicine is an applied science like engineering; however, the social acceptance of science is attributed to its powerful engineering products.

A scientific theory, says Lakatos, ${ }^{3}$ must have 'positive heuristics'; i.e. 'problem-solving'; e.g. Einstein's general theory of relativity solved the planet Mercury's problematic orbit, while certain theories were verified by 'dramatic confirming instances' and not 'crucial experiments'; e.g. Newton's laws were accepted after Halley's Comet's calculated return 72 years later. ${ }^{3}$ The high quality of a technology must be designed into it from the outset - it won't work better than originally designed. And, scientific evidence is depicted by, e.g., the first flight of Airbus A380 aircraft, one assembled aircraft - a high- 
quality product demonstrated outside the laboratory. Furthermore, it is inept to experiment on a mature product.

HTS has 'positive heuristics'. They approximate therapeutic certainty, designed into medicines from the outset, so achieving the aim of the profession - a 'right and good healing action taken in the interest of a particular patient', one patient, achieved not 'fortuitously', otherwise the profession is 'inauthentic and a lie. ${ }^{3}$ Its scientific evidence is its clinical successes, its 'confirming instances' or 'anecdotes' in, e.g., cholera epidemics. Nevertheless, HTS can't replace, for example, lignocaine or surgery.

In conclusion, Hahnemann's system isn't a 'mystica', and this letter is based on an article published elsewhere. ${ }^{5,6}$

\section{Herman Jeggels}

$M D$ (VU Ams), MRCP (UK), FBIH (Hon), DHM (Hon)

General Practitioner

hjdj@jeggels.com

Van Niekerk JP. Traditional healers formalised? S Afr Med J 2012;102(3):105-106

2. Ameke W. History of Homoeopathy: Its Origin, Its Conflicts. London: E Gould \& Son, 1885.

. Ameke W. History or Hon

4. Pellegrino E. Toward a reconstruction of medical morality: the primacy of the act of profession and the

fact of illness. Med Philos 1979;4(1).

The

Jeggels HJD. An Analysis of the concept scientific evidence of technologies as it relates to NASA TRLs \& technoscience, medicine, and homoeopathic therapeutics, Part 1. The Homoeopathic Herita

6. Jeggels HID. An Analysis of the concept scientific evidence of technologies as it relates to NASA' TRLs \& technoscience, medicine, and homoeopathic therapeutics, Part 2. The Homoeopathic Heritag 2012;38(2):23-30.

\section{Is Hahnemann's therapeutic system a mystica? The managing editor replies}

Dr Jeggels' response is difficult to follow but the main claim is that homeopathy is scientifically valid. However, for acceptance, such claims must meet scientific standards.

At the time that Hahnemann made his 'discoveries' his treatment was safer than conventional medicine that prescribed bloodletting, purges and harmful substances in the belief that they worked, usually to the detriment of the patient. But medicine changed its beliefs by embracing science, whereas homeopathy shores up the defences of its beliefs.

Homeopathic claims run counter to science: the claim that 'like cures like' has been compared to vaccination, where an attenuated organism or a close relative of the organism imparts immunity However, vaccination results can be measured by rising antibodies, reducing the outbreaks of disease (e.g. wiping smallpox off this planet) etc., whereas homeopathic treatment has no measurable change. Their claim that 'the greater the dilution the greater the therapeutic effect' cannot be substantiated scientifically and, if true, would require a complete rewrite of scientific facts. Ah, but it is the preparation of the dilutions (by shaking the mixture) that changes the water molecules so that the therapeutic message that is supposed to reside in the product being diluted is remembered and enhanced in the water molecules. The scientist who claimed to have proved this has been discredited as others could not replicate his findings (required for scientific validation) and which he could not repeat in his laboratory in the presence of a team of scientists sent to review his work.

Thus, in scientific terms, homeopathic medicines do no harm as they contain no active ingredient (though they are harmful when used in place of medication that has measurable benefits, e.g. insulin in diabetes and antiretroviral drugs for AIDS). Homeopathic medicines do indeed also have beneficial effects - but no different from the placebo effect.
Misquoting science to support a belief is non-science and homeopathy remains firmly in the domain of truth called mystica.

\author{
J P van Niekerk \\ Managing Editor \\ South African Medical Journal \\ jpvann@hmpg.co.za
}

S Afr Med J 2012;102(8):640-641. DOI:10.7196/SAMJ.6078

\section{The occupational illnesses of grandparents}

To the Editor: While visiting our kids and grandson last year, I had a recurring thought: being a grandparent is not for 'sissies'. My wife and I thought about how grandparenting challenged our health; each day saw some insult to body homeostasis and we were grateful each night for another day survived. Don't get me wrong, we wouldn't trade days with our little man for all the gold in China or the USA, but I came to think that grandparents are special people, not for giving love or gifts, but for putting our bodies on the line. Occupational illness is a given - the Compensation Commissioner needs to take note.

Lest you think I exaggerate, here is our list of illnesses and traumas faced, which could probably be lengthened significantly: colds and 'flu; injuries from thrown objects; head-banging and neck-crunching injuries; loud-noise deafness; side-aching laughter to strain the torso muscles - at the words, utterances, make-believe acts and other wonderful goings-on; muscle strains and sprains; hernias from lifting heavy objects (including grandchildren); unknown infectious illnesses; nappy change and 'potty'-induced gastrointestinal upsets (nausea and vomiting); oral and gastrointestinal upsets from ingestion of partially chewed sweets; sunburn/frostbite from playing outside; inhalation of noxious gasses emitted (mostly from the toddler's gastrointestinal tract); hoarse voice from continual chitterchatter and praise of 'poos', 'wees', verbal utterances and the like; and a broken heart upon departure.

Expanding on these concerns, firstly, is the continuous threat to the upper respiratory tract from a myriad of viruses and bugs, some of which must be new to medical science. They are certainly new to our immune systems; our bags are no sooner unpacked than the sniffles begin. Our grandson has 12 upper respiratory tract infections per year, all seemingly in the fortnight that we spend with him. There is the 'snot ball monster' walking towards you in dire need of a tissue, while your stomach churns and you frantically reach for any piece of paper or clothing to contain the outburst! Frequently it is your hand that must come to the rescue, and allow that wonderful smile to emerge with a gentle thanks.

Then come rounds of bruising encounters with toys, some in flight just as you take your eye off them. The head seems to take the most battering: a favourite gesture is to touch you on the forehead, lovingly, but sadly with no concept of distance. These loving embraces may leave a bruise, egg-shaped protrusion, or even a black eye, as though one survived an encounter with Mike Tyson. The body's integument, while covered in bruises, takes on shades of the prevailing season red in summer and blue in winter - as young men need their daily fix of the sun, no matter what the outside temperature.

The gastrointestinal tract seems to take the biggest hit: those gutwrenching nappy changes and the bugs that accompany partially digested candy that 'Ampies' has to suck when found not palatable by young mouths; the insistence, as he gets older, that 'Ampies' has to wipe his bum; and, of course, the encouragement and coercion 


\section{CORRESPONDENCE}

that goes with thinking to 'go potty' and having to inspect the result afterwards and heap praise on how wonderful you think it is!

All too early, the holiday ends and the hardest trauma to bear comes hurtling in; the pain inflicted on the heart by the sadness of goodbye. If, like us, you live in a foreign land, then the parting is most acute. The precious hand-to-mouth gesture of blowing kisses and words of 'I uff you Ampies' makes me need to walk away to gain composure. These are the aches and pains we endure as our grandchildren grow up. Despite all of this, and the lack of compensation, we would not have it any other way. Grandparents are the luckiest humans alive. Love heals all, memories are forever.

\section{Robin J Green}

Department of Paediatrics and Child Health

University of Pretoria

\section{Dee Green}

Occuhealth

Johannesburg

S Afr Med J 2012;102(8):641-642. DOI:10.7196/SAMJ.5976

\section{The South African paediatric tumour registry - 25 years of activity}

To the Editor: We appreciate Drs Stefan and Stones highlighting the value of cancer registries. ${ }^{1}$ Establishing a comprehensive population-based cancer registry in South Africa is most important and long overdue. This does not preclude specialised registries, provided that all cancers are reported to the main, statutory registry. Best practice is inclusive reporting of all cancers to a single registry for all age groups, which enables national trends to be described for the entire South African population, including rural areas. Recently, the National Cancer Registry (NCR) has received renewed support from the National Department of Health and the NHLS, as they have increased the focus of health services towards the expanding chronic disease epidemics, which has also motivated the NCR to initiate a hospital-based registry in Ekurhuleni (Gauteng Province) to pilot reporting on the new forms.

The new cancer regulations (Act No. 61 of 2006 No. R.380) require every healthcare provider who diagnoses or treats cancer in a patient to report to the NCR using the statutory form. ${ }^{2}$ Duplicates are valuable to provide complete information and to ensure that no cases are missed. Overall compliance, 14 months after gazetting, has been slow and at times incomplete. Some respondents, for example, did not complete the risk factor section. Compliance by paediatric oncologists has been good. This kind of comprehensive information can be used for research and to assist planning for increased provision of diagnostic, preventive and treatment services.

Improved collaboration between various cancer service providers, researchers and other interest groups in South Africa is pivotal for enhancing cancer services, facilitating much-needed research into cancer risks, incidence and survival, and providing increased capacity for prevention and education. NCR data are available on formal request. For NCR statistics from 2000 - 2004, including age-specific rates and information on the new cancer regulations, access the National Institute for Occupational Health website (www.nioh.ac.za; publications; cancer statistics) or by directly contacting the National Cancer Registry.

\section{Danuta Kielkowski \\ Elvira Singh \\ Kerry Wilson \\ Chantal Babb \\ Margaret Urban \\ Patricia Kellett}

National Cancer Registry, NHLS

Johannesburg

kerry.wilson@nioh.nhls.ac.za

1. Stefan DC, Stones DK. The South African paediatric tumour registry - 25 years of activity. S Afr Med J 2012;102(7):605-606.

Regulations Relating to Cancer Registration. National Health Act, 2003. Pretoria: Government Gazette 26 April 2011.

S Afr Med J 2012;102(8):642. DOI:10.7196/SAMJ.6113

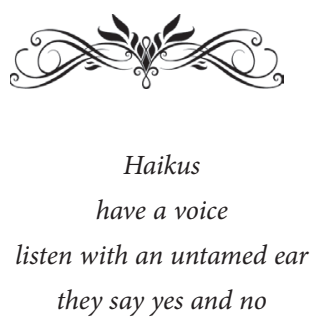

